\title{
A Buck-Boost Type Charger with a Switched Capacitor Circuit
}

\author{
Jinn-Chang $\mathrm{Wu}^{\dagger}$, Hurng-Liahng Jou* , and Jie-Hao Tsai ${ }^{* *}$ \\ $\dagger^{* *}$ Dept. of Microelectronics Engineering, National Kaohsiung Marine University, Kaohsiung, Taiwan \\ *Dept. of Electrical Engineering, National Kaohsiung University of Applied Sciences, Kaohsiung, Taiwan
}

\begin{abstract}
In this paper, a buck-boost type battery charger is developed for charging battery set with a lower voltage. This battery charger is configured by a rectifier circuit, an integrated boost/buck power converter and a switched capacitors circuit. A boost power converter and a buck power converter sharing a common power electronic switch are integrated to form the integrated boost/buck power converter. By controlling the common power electronic switch, the battery charger performs a hybrid constant-current/constant-voltage charging method and gets a high input power factor. Accordingly, both the power circuit and the control circuit of the developed battery charger are simplified. The switched capacitors circuit is applied to be the output of the boost converter and the input of the buck converter. The switched capacitors circuit can change its voltage according to the utility voltage so as to reduce the step-up voltage gain of the boost converter when the utility voltage is small. Hence, the power efficiency of a buck-boost type battery charger can be improved. Moreover, the step-down voltage gain of the buck power converter is reduced to increase the controllable range of the duty ratio for the common power electronic switch. A prototype is developed and tested to verify the performance of the proposed battery charger.
\end{abstract}

Key words: Active damping, DFT, LCL filter, Resonance, Wind power system

\section{INTRODUCTION}

Portable electronic products and electric bikes have become more popular due to the progress of the battery industry in recent years. The performance of batteries significantly affects the operation of portable electronic products and electric bikes. The performance and lifetime of a battery is affected by the battery charger. Therefore, the operation of a battery depends on a battery charger with good controllability.

Battery chargers for portable electronic products and electric bikes require a power source with a low DC voltage. However, distribution power systems supply a high AC voltage. Therefore, a battery charger acts as an interface between a distribution power system and the battery set. Conventionally, a diode rectifier with a filter capacitor is

Manuscript received Feb. 12, 2014; accepted Aug. 21, 2014

Recommended for publication by Associate Editor Joung-Hu Park.

†Corresponding Author: jinnwu@mail.nkmu.edu.tw

Tel: +886-7-3917141, Fax: +886-7-3645589, NKMU

${ }^{*}$ Dept. of Electrical Eng., Nat'1 Kaohsiung Univ. of Applied Sci., Taiwan

** Dept. of Microelectronics Eng., Nat'l Kaohsiung Marine Univ., Taiwan applied to convert AC power into DC power for charging a battery set due to its simple configuration and low cost [1]. Unfortunately, the output voltage of a diode rectifier cannot be regulated according to the state of charge (SOC) of the battery set, which will shorten the life of the battery set. In addition, its input characteristic is nonlinear, resulting in harmonic current and a poor power factor. The output voltage of the diode rectifier is about the peak value of the input $\mathrm{AC}$ voltage, and it cannot directly charge the battery set with a low DC voltage. A low-frequency transformer needs to be placed at the front of the diode rectifier, which will increase the volume and weight of the battery charger.

For lowering and regulating the output voltage, a buck converter can be connected to the diode rectifier in cascade [2]-[4]. The diode rectifier outputs an absolute voltage of the utility voltage, and the buck converter converts the absolute voltage into a regular voltage with a low DC voltage. The power electronic switch of the buck converter can be controlled to regulate the output voltage according to the SOC of the battery set. It also corrects the input current of the diode rectifier to be approximately sinusoidal. However, the buck converter cannot work when the absolute voltage is 
lower than the output voltage, and the input current of the diode rectifier is zero. Hence, the input current will contain a zero-crossing distortion. In addition, the duty ratio of the power electronic switch will be small for obtaining a high step-down voltage gain, and it is difficult to precisely control the output voltage. To avoid zero-crossing distortion of the input current, the buck converter can be replaced by a flyback converter [5], [6] or a buck-boost converter [7], [8]. A high-frequency transformer is used in the flyback converter to increase the step-down voltage gain. Although the size of the high-frequency transformer is small, it will result in an extra power loss and it will increase the voltage rating of the power electronic switch. The power factor corrector, which is configured by a diode rectifier and a boost converter, can solve the problem of zero-crossing distortion [9]-[14]. The input current will be sinusoidal and in phase with the input $\mathrm{AC}$ voltage to achieve a unity power factor. However, the output voltage will be higher than the peak value of the input AC voltage, and it cannot directly charge the low-voltage battery set. An extra buck converter or a flyback converter, which achieves a high step-down gain, needs to be connected to the output of the power factor corrector for generating a low DC voltage. This is a two-stage AC-DC power converter and it complicates both the power circuit and the control circuit. In addition, the step-up voltage gain for the power factor corrector is very high when the amplitude of the utility voltage is low. Considering the parasitic resistor of the inductor and ignoring the power loss of the power semiconductor devices, the power efficiency of a boost power converter can be derived as:

$$
\zeta=\frac{1}{1+\mathrm{r}_{\mathrm{L}} / \mathrm{R}\left(1-\mathrm{D}_{\mathrm{b}}\right)^{2}}
$$

where $r_{L}$ and $R$ are the parasitic resistor of the inductor and the equivalent load resistor, and $D_{b}$ is the duty of the power electronic switch [1]. As seen in (1), the efficiency of the boost converter is evidently degraded under a high step-up voltage gain. Hence, the efficiency of the boost converter is very low for the duration of low utility voltage. Since the valley-fill circuit performs the series-charging and parallel-discharging of the capacitors, it can be used in the AC-DC power converter to reduce the required capacity of bulky electrolytic capacitors [15]-[17]. However, the step-up voltage gain for the valley-fill circuit based AC-DC power converter is very high when the amplitude of the utility voltage is low. The power efficiency of a boost power converter has been analyzed in [18]. If the power loss of the power semiconductor devices is considered, the power efficiency of the boost power converter will be further degraded after considering the power loss of the power semiconductor devices, and it is inversely proportional to the ratio $r_{L} / R$ under the higher duty of the power electronic switch [18]. This means that the power efficiency of a boost power converter with a higher duty will be significantly

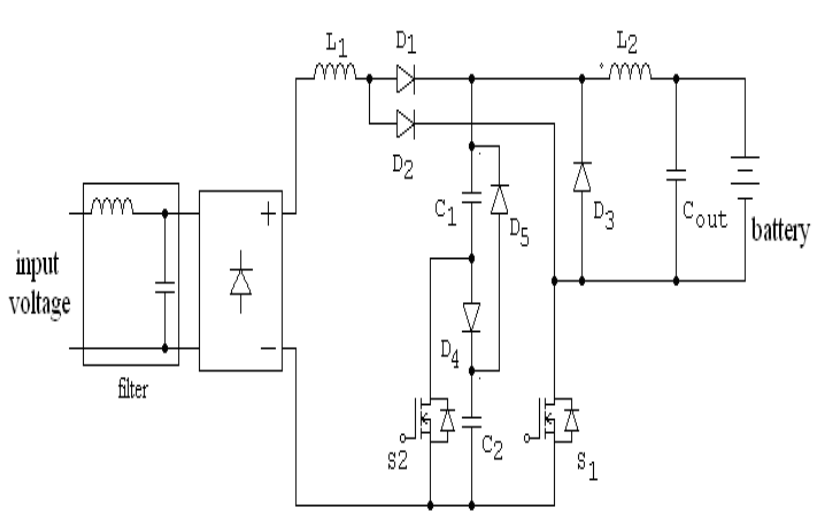

Fig. 1. Circuit configuration of the proposed buck-boost type battery charger.

degraded under a light load.

In this paper, a buck-boost type battery charger is developed. The developed battery charger is configured by a rectifier circuit, an integrated boost/buck power converter, and a switched capacitors circuit. The boost/buck power converter integrates a boost power converter and a buck power converter to simplify the power circuit. The switched capacitors circuit is applied to reduce the step-up voltage gain of the boost power converter and to increase the step-down voltage ratio of the buck power converter. As a result, the efficiency of the buck-boost type battery charger is improved.

\section{CIRCUIT CONFIGURATION}

Fig. 1 shows the circuit configuration of the proposed buck-boost type battery charger. The output current/voltage can be regulated according to the SOC of the battery set, and the input current can be controlled to be approximately sinusoidal and in phase with utility voltage to achieve a high power factor. As seen in Fig. 1, the proposed buck-boost type battery charger is composed of a diode rectifier, an integrated boost/buck power converter, and a switched capacitors circuit. The diode rectifier converts the utility voltage to an absolute voltage. To perform the function of power factor correction, a boost converter needs to be connected to the output of the diode rectifier. In addition, a buck converter should be applied to step down the output voltage of the boost converter to match the voltage of the battery set. In the proposed buck-boost type battery charger, a boost power converter and a buck power converter are integrated to form an integrated boost/buck power converter. As seen in Fig. 1, the boost converter is configured by inductor L1, diodes D1 and D2, and power electronic switch S1. For the boost converter, the input is connected to the output of the diode rectifier and the output is connected to the switched capacitor circuit.

The buck converter is configured by diode D3, inductor L2 and power electronic switch S1. The input of the buck converter is connected to the switched capacitor circuit and its output is used to charge the battery set. Accordingly, 
power electronic switch S1 is used in the boost converter and the buck converter simultaneously. The switched capacitor circuit is configured by power electronic switch S2, capacitors $\mathrm{C} 1$ and $\mathrm{C} 2$, and diodes D4 and D5. The switched capacitor circuit is similar to a valley-fill circuit. However, the power electronic switch of the switched capacitor circuit replaces the diode of the valley-fill circuit. Accordingly, capacitors $\mathrm{C} 1$ and $\mathrm{C} 2$ can be operated as individual capacitor charging, series charging two capacitors or parallel discharging two capacitors, depending on the states of power electronic switches S1 and S2 and the amplitude of the utility voltage. This is different from the valley-fill circuit where the two capacitors can only be charged in series.

\section{OPERATION PRINCIPLE}

\section{A. Switched Capacitor Circuit}

In a conventional power factor corrector, the utility voltage is converted to an absolute voltage by a diode rectifier, and then a boost converter is used to control the waveform of the input current and to regulate the output DC voltage. For nominal operation, the output DC voltage needs to be higher than the peak value of the utility voltage. For a small-capacity power factor corrector, the boost converter is generally operated in the discontinuous conduction mode (DCM) to reduce the size of the inductor and to achieve zero current switching. However, the operation of the DCM for a boost converter will increase the output DC voltage to further increase the voltage gain. Unfortunately, the higher the voltage gain of a boost converter is, the lower its power efficiency will be [1]. In particular, the voltage gain is very high when the amplitude of the utility voltage is low for applying the boost converter in the power factor corrector. Accordingly, the power efficiency of the power factor corrector is degraded.

For decreasing the voltage gain of the boost converter under a low amplitude utility voltage, the output of the boost converter is connected to the switched capacitor circuit in the proposed buck-boost type charger. Power electronic switch $\mathrm{S}_{2}$ is used in the switched capacitor circuit, which is different from a valley-fill circuit. When the absolute voltage of the utility voltage is smaller than half of its peak voltage, $S_{2}$ is in the on-state. At this time, only capacitor $\mathrm{C}_{1}$ of the switched capacitor circuit is connected to the output of the boost converter. Accordingly, the output voltage of the boost converter is equal to capacitor voltage $\mathrm{V}_{\mathrm{Cl}}$. Since capacitors $\mathrm{C}_{1}$ and $\mathrm{C}_{2}$ discharge power to the buck converter in parallel, their voltages will be balanced automatically. This means that capacitor voltage $\mathrm{V}_{\mathrm{C} 1}$ is about half of the $\mathrm{DC}$ output voltage for a conventional power factor corrector. This is different from the valley-fill circuit based AC-DC power converter, where the output voltage is still two times the individual capacitor voltage. Therefore, the voltage gain of the boost

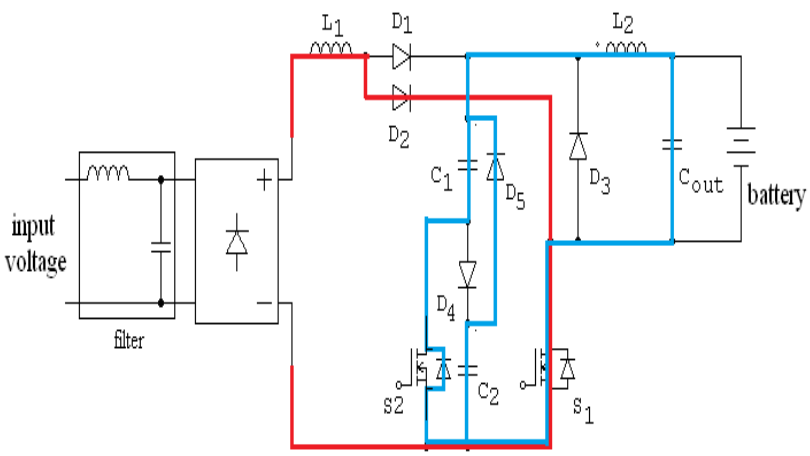

Fig. 2. Conducting path of integrated boost/buck power converter when $S_{1}$ is in the on-state.

converter in the integrated boost/buck power converter is half that of a conventional power factor corrector and the valley-fill circuit based AC-DC power converter when the amplitude of the utility voltage is smaller than half of its peak voltage. As a result, the power efficiency is improved. When the amplitude of the utility voltage is higher than half of its peak voltage, $S_{2}$ is in the off-state. Capacitors $C_{1}$ and $C_{2}$ are connected in series through $\mathrm{D}_{4}$ and then connected to the output of the boost converter. At this time, the output voltage of the boost converter in the integrated boost/buck power converter is similar to that of a conventional power factor corrector and the valley-fill circuit based AC-DC power converter. From the above, the output voltage of the boost converter in the integrated boost/buck power converter can be divided into two levels by controlling the state of $S_{2}$ in the switched capacitor circuit. As a result, the power efficiency of the buck-boost type battery charger will be improved.

\section{B. Integrated Boost/Buck Power Converter}

The integrated boost/buck power converter is composed of a boost converter and a buck converter sharing a power electronic switch $S_{1}$. Fig. 2 shows the conducting path of the integrated boost/buck power converter when $S_{1}$ is in the on-state. The red line shows the conducting path for the boost converter. The current of inductor $\mathrm{L}_{1}$ of the boost converter can be represented as:

$$
\frac{d i_{L 1}}{d t}=\left|v_{s}\right| / L_{1}
$$

where $\mathrm{v}_{\mathrm{s}}$ is the utility voltage. The current of inductor $\mathrm{L}_{1}$ will increase to store energy from the utility voltage. The blue line shows the conducting path of the buck converter. Capacitors $\mathrm{C}_{1}$ and $\mathrm{C}_{2}$ are connected in parallel through the parallel diode of $S_{2}$ and $D_{5}$. Then they supply power to the buck converter. The current of inductor $\mathrm{L}_{2}$ of the buck converter can be represented as:

$$
\frac{d i_{L 2}}{d t}=\left(V_{c}-V_{o}\right) / L_{2}
$$

where $\mathrm{V}_{\mathrm{c}}$ is the higher voltage among $\mathrm{C}_{1}$ or $\mathrm{C}_{2}$, and $\mathrm{V}_{\mathrm{o}}$ is the output voltage. Since $C_{1}$ and $C_{2}$ are discharged in parallel, the 


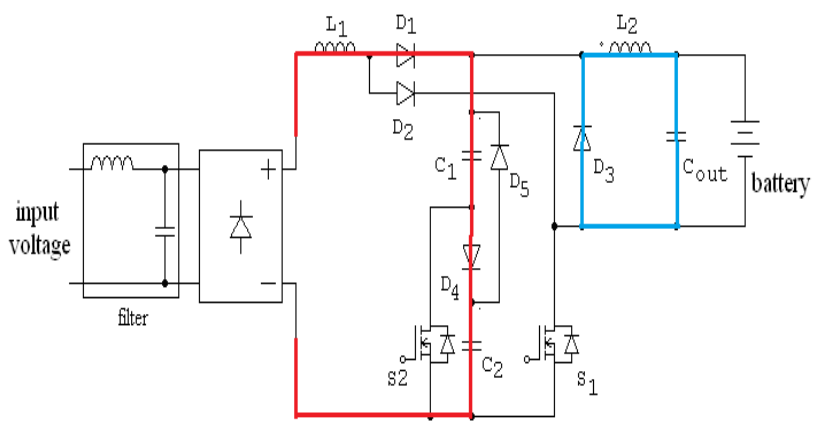

(a)

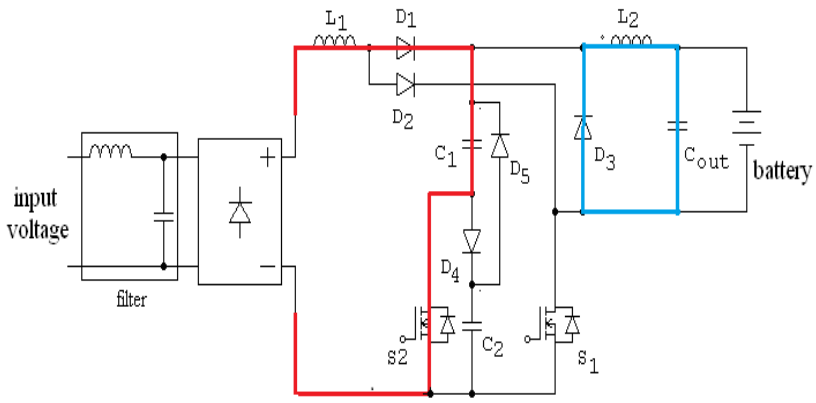

(b)

Fig. 3. Conducting path of integrated boost/buck power converter when $S_{1}$ is in the off-state. (a) $S_{2}$ is in the off-state. (b) $S_{2}$ is in the on-state.

capacitor with the higher voltage will discharge more power. Accordingly, the voltages of $\mathrm{C}_{1}$ and $\mathrm{C}_{2}$ will be balanced. The current of inductor $\mathrm{L}_{2}$ will increase to store energy from the switched capacitor circuit.

Fig. 3 shows the conducting path of the integrated boost/buck power converter when $\mathrm{S}_{1}$ is in the off-state. The integrated boost/buck power converter contains two conducting paths, depending on the state of $\mathrm{S}_{2}$. As seen in Fig. 3(a), the energy stored in $\mathrm{L}_{1}$ of the boost converter will charge $C_{1}$ and $C_{2}$ in series through $D_{1}$ when $S_{2}$ is in the off-state, and the current of $\mathrm{L}_{1}$ can be represented as:

$$
\frac{d i_{L 1}}{d t}=\left|v_{s}\right|-\left(V_{c 1}+V_{c 2}\right) / L_{1}
$$

where $\mathrm{V}_{\mathrm{C} 1}$ and $\mathrm{V}_{\mathrm{C} 2}$ are the voltages of $\mathrm{C}_{1}$ and $\mathrm{C}_{2}$, respectively. As seen in Fig. 3(b), when $S_{2}$ is in the on-state, the energy stored in $\mathrm{L}_{1}$ only charges $\mathrm{C}_{1}$, and the current of $\mathrm{L}_{1}$ can be represented as:

$$
\frac{d i_{L 1}}{d t}=\left|v_{s}\right|-V_{c 1} / L_{1}
$$

The current of inductor $\mathrm{L}_{1}$ decreases to release its energy. The energy stored in $\mathrm{L}_{2}$ of the buck converter will charge output capacitor $C_{\text {out }}$ through $\mathrm{D}_{2}$ regardless of the state of $\mathrm{S}_{2}$, and the current of $\mathrm{L}_{2}$ can be represented as:

$$
\frac{d i_{L 2}}{d t}=-V_{o} / L_{2}
$$

The current of $\mathrm{L}_{2}$ will decrease.

From the above, it can be seen that both $C_{1}$ and $C_{2}$ supply power to the buck converter in parallel. It can also be seen that the input voltage of the buck converter in the integrated boost/buck power converter will be half of the output voltage of the conventional power factor corrector. Hence, the integrated boost/buck power converter can increase the step-down voltage ratio when compared with topologies where the boost converter and the buck converter are connected in cascade. Therefore, the duty ratio of the buck converter in the integrated boost/buck power converter can be extended when compared to that connected to the output of the conventional power factor corrector. In addition, the difficulty in precisely controlling the output voltage can be alleviated.

The boost converter of the integrated boost/buck power converter is operated in the DCM. The variation of $i_{L 1}$ under the on-duration of $\mathrm{S}_{1}$ can be represented as:

$$
\Delta I_{L 1, \text { on }}=\left|v_{S}\right| D T / L_{1}
$$

where $\mathrm{D}$ is the duty of $\mathrm{S}_{1}$, and $\mathrm{T}$ is the switching period. The variation of $i_{L 1}$ under the off-duration of $S_{1}$ can be represented as:

$$
\Delta I_{L 1, \text { off }}=\left(\left|v_{s}\right|-V_{x}\right) t_{\text {fall }} / L_{1}
$$

where $V_{x}$ may be $V_{C}$ or $V_{C 1}+V_{C 2}$ depending on the state of $S_{2}$, and $t_{\text {fall }}$ is the falling time of $i_{\mathrm{L} 1}$. The boost converter is operated in the discontinuous conduction mode, and:

$$
\Delta I_{L 1, \text { on }}=\Delta I_{L 1, \text { off }}
$$

From (6)-(8), $\mathrm{t}_{\text {fall }}$ can be derived and represented as:

$$
t_{\text {fall }}=\frac{\left|v_{s}\right|}{V_{x}-\left|v_{s}\right|} D T
$$

$\mathrm{t}_{\text {fall }}$ should be smaller than the off time (1-D)T of $\mathrm{S}_{1}$. By combining (6) and (7), the average current of $L_{1}$ can be derived as:

$$
i_{L 1, \text { avg }}=\frac{1}{2}\left(D T+t_{\text {fall }}\right) \frac{\left|v_{s}\right|}{L_{l}} D T
$$

Substituting (9) into (10), the average current of $\mathrm{L}_{1}$ can be rewritten as:

$$
i_{L 1, a v g}=\frac{1}{2}\left(\frac{V_{x}}{V_{x}-\left|v_{S}\right|}\right) \frac{\left|v_{s}\right|}{L_{1}} D^{2} T^{2}
$$

Since power electronic switch $S_{1}$ is shared by the boost converter and the buck converter in the integrated boost/buck power converter, the duty $\mathrm{D}$ can be used to control only one object. In the buck-boost type charger, the control object can be either the input current of the boost converter or the output current/voltage of the buck converter. As can be seen in (12), the average current of $\mathrm{L}_{1}$ is not directly proportional to the absolute value of the utility voltage. This means that the input current of the buck-boost type battery charger will be distorted if the duty ratio of $S_{1}$ is fixed. For obtaining a unity power factor, the control object of the buck-boost type battery charger is the input current of the boost converter. The input 
current of the boost converter needs to be proportional to the utility voltage, and it can be represented as:

$$
\frac{1}{2}\left(\frac{V_{x}}{V_{x}-\left|v_{s}\right|}\right) \frac{\left|v_{s}\right|}{L_{l}} D^{2} T^{2}=k\left|v_{s}\right|
$$

where $\mathrm{k}$ is a constant, which determines the input power of the buck-boost type charger. Accordingly, from the point of view of the utility voltage, the buck-boost type battery charger can be operated as a resistor $1 / k$. From (13), the duty of $\mathrm{S}_{1}$ can be derived as:

$$
\begin{aligned}
D & =\sqrt{\frac{2 L_{1} k}{T^{2}}\left(1-\frac{\left|v_{s}\right|}{V_{x}}\right)} \\
& =k^{\prime} \sqrt{1-\frac{\left|v_{s}\right|}{V_{x}}}
\end{aligned}
$$

where:

$$
k^{\prime}=\sqrt{\frac{2 L_{1} k}{T^{2}}}
$$

If the duty of $S_{1}$ can be controlled to follow (14), the buck-boost type charger can be operated as a resistor to achieve a unity power factor. The real power injected into the buck-boost type charger can be regulated by k' to control the charging power of the battery set. The buck converter of the integrated boost/buck power converter is operated in the continuous conduction mode. Pulse-width modulation (PWM) is used to control $\mathrm{S}_{1}$. The voltage across diode $\mathrm{D}_{3}$ is a pulse voltage with an amplitude of $\mathrm{V}_{\mathrm{Cl}}$, and its average voltage $\mathrm{V}_{\mathrm{D} 3}$ can be represented as:

$$
\mathrm{V}_{\mathrm{D} 3}=D V_{C 1}
$$

The output voltage of the buck converter is the average voltage $V_{D 3}$ because $L_{2}$ and $C_{\text {out }}$ are operated as a second low-pass filter. Since the battery set can be regarded as a voltage source with a small internal resistor, the output voltage of (16) will result in a large ripple integrated into the charging current of the battery set.

For achieving constant-current/constant-voltage charging of the battery set, the control object of the buck-boost type battery charger is the output current/voltage of the buck converter. If the ripple voltage of the switched capacitors circuit is ignored, the duty $\mathrm{D}$ is almost constant. The average current of $\mathrm{L}_{1}$ is shown as (12), and it results in a distortion in the input current of the buck-boost type charger.

Figs. 4 and 5 show simulation results of the buck-boost type charger. The parameters of the buck-boost type charger are shown in Table I. Fig. 4 shows the input current and charging current of the buck-boost type charger when the control object is the input current of the boost converter. As seen in Fig. 4(a), the input current of the buck-boost type charger is sinusoidal. However, the charging current of the battery set, shown in Fig. 4(b), contains a large ripple. Fig. 5 shows the input current and charging current of the buck-boost type charger when the control object is the output

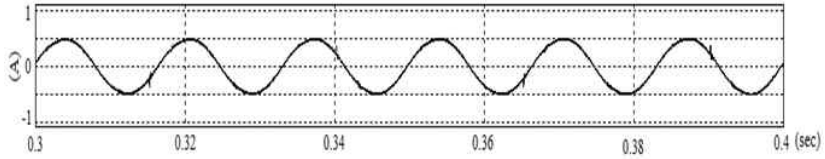

(a)

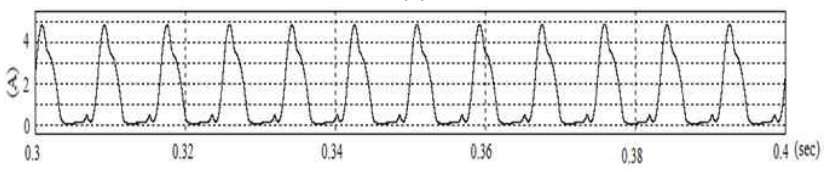

(b)

Fig. 4. Simulation results of the buck-boost type charger when the control object is the input current. (a) Input current. (b) Charging current.

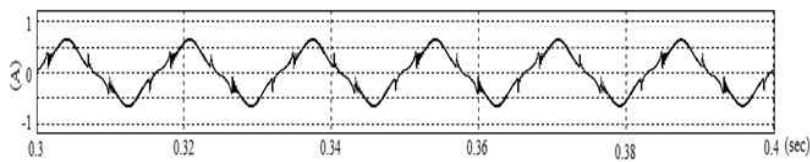

(a)

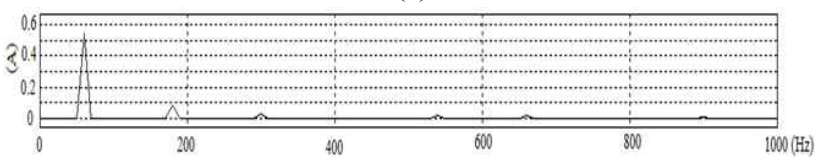

(b)

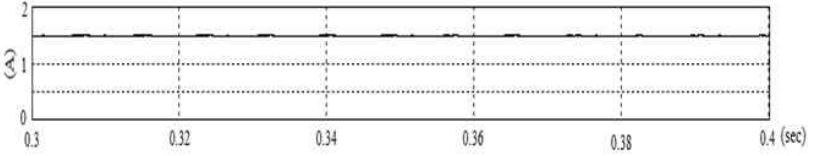

(c)

Fig. 5. Simulation results of the buck-boost type charger when the control object is the charging current. (a) Input current. (b) Spectrum of input current. (c) Charging current.

current of the buck converter. As seen in Fig. 5(a), the input current of the buck-boost type charger is slightly distorted. The spectrum of the input current is shown in Fig. 5(b). The total harmonic distortion (THD\%) of the input current is about $17 \%$. The ripple of the charging current of the battery set, shown in Fig. 5(c), is small.

When compared with the conventional two-stage AC-DC power converter, the proposed buck-boost type battery charger integrates a boost power converter and a buck power converter to simplify both the power circuit and the control circuit. Since the control of the boost power converter and the buck power converter is integrated, the response of the proposed buck-boost type battery charger is superior to that of the conventional two-stage AC-DC power converter where the control is separated. In addition, the problems of the high voltage gain under the low amplitude of utility voltage for the boost power converter, the small duty for the high step-down voltage gain for the buck power converter and the bulky electrolytic capacitor are improved in the proposed buck-boost type battery charger. Although the valley-fill circuit based AC-DC power converter can solve the problems of the small duty of the high step-down voltage gain for the buck power converter and the bulky electrolytic capacitor 
[15]-[17], the problem of the high voltage gain under the low amplitude of utility voltage for the boost power converter cannot be solved. When compared with the buck converter based AC-DC power converter [2]-[4], the power circuit is complicated and the power efficiency is degraded for the proposed buck-boost type battery charger. However, the serious problem of zero-crossing distortion, which results in a high distortion of the input current, is solved in the proposed buck-boost type battery charger.

\section{CONTROL BLOCK DIAGRAM}

For considering the charging performance, the control object of the buck-boost type battery charger is the output current/voltage of the buck converter. Fig. 6 shows a control block diagram of the proposed buck-boost type charger. The hybrid constant-current/constant-voltage charging method is applied to charge the battery set. If the voltage of the battery set is lower than the preset voltage, the battery charger charges the battery set with a constant current. On the other hand, the battery charger charges the battery set at a constant voltage when the voltage of the battery set is higher than the preset voltage. The voltage and current of the battery set are detected by a voltage sensor and a current sensor. The detected voltage and current of the battery set are sent to the inputs of the controllable switch. The position of the controllable switch depends on which charging mode of the battery set is selected. The output of the controllable switch is sent a comparator to compare it with a setting value, and the compared result is sent to the PI controller. For simplifying the controller, the gains of the voltage sensor and the current sensor are adjusted so as to unify the setting value for the constant voltage charging and constant current charging of the battery set. Since the change for the voltage and current of the battery set is slow, the parameters of the PI controller are not critical. The output of the PI controller is sent to the PWM circuit to obtain the control signal of $S_{1}$. The utility voltage is detected by a voltage sensor and sent to the absolute circuit. The absolute utility voltage is sent to a comparator to be compared with $\mathrm{V}_{\mathrm{s}} / 2$, which is half the amplitude of the utility voltage. The output of the comparator is the control signal of $\mathrm{S}_{2}$.

The PI controller can be represented as:

$$
\mathrm{G}_{\mathrm{c}}(\mathrm{s})=\frac{k_{p} s+k_{i}}{s}
$$

The duty of $\mathrm{S}_{1}$ can be represented as:

$$
\mathrm{D}=\frac{v_{m}}{V_{t r i}}
$$

where $\mathrm{V}_{\mathrm{m}}$ is the modulation signal, and $\mathrm{V}_{\text {tri }}$ is the amplitude of the carrier signal for the PWM circuit. Referring to (16)-(18), the model of the buck converter operated under charging by a constant-current, is shown in Fig. 7. In Fig. 7, $\mathrm{k}_{\text {cur }}$ is the gain

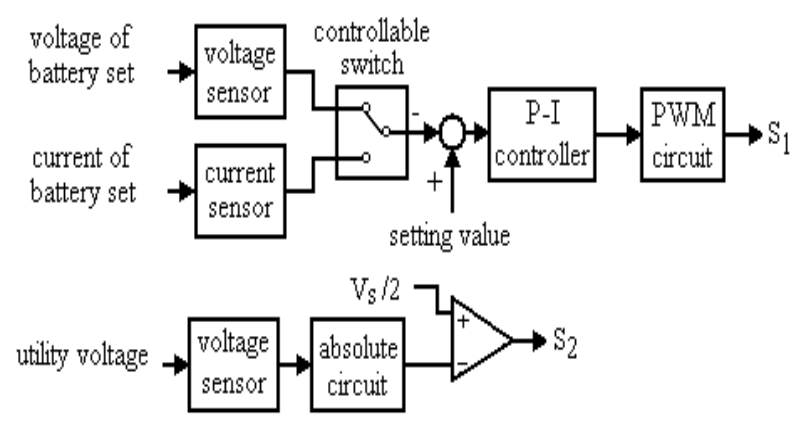

Fig. 6. Control block of the buck-boost type charger.

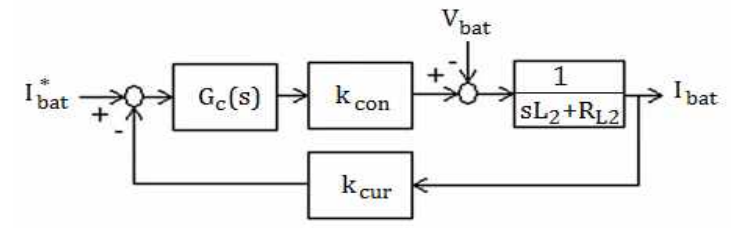

Fig. 7. Model of buck converter.

of the current sensor and $\mathrm{R}_{\mathrm{L}}$ is the stray resistor of $\mathrm{L}_{2} . \mathrm{k}_{\text {con }}$ is the gain of the buck converter and it can be represented as:

$$
\mathrm{k}_{c o n}=\frac{V_{c 1}}{V_{t r i}}
$$

\section{EXPERIMENTAL RESULTS}

To verify the performance of the proposed buck-boost type charger, a prototype, using a DSP TMS320F28035 as a controller, was developed and tested. The parameters of the prototype are shown in Table I. The battery set is configured by connecting two lead-acid batteries in series. The utility voltage is from a single-phase distribution power system with a voltage and frequency of $110 \mathrm{~V}$ and $60 \mathrm{~Hz}$, respectively. Since the change in the voltage and current of the battery set is slow, the phase margin for the buck-boost type battery charger is not critical. According to the model of Fig. 7, the phase margin for the buck converter is about $90^{\circ}$ under charging by a constant-current.

Fig. 8 shows the experimental results of the input characteristic for the proposed buck-boost type charger. As seen in Fig. 8(a), the input current is approximately sinusoidal and in phase with the utility voltage. The power factor is 0.93 . As seen in Fig. $8(\mathrm{~b})$, the THD $\%$ of the input current is $16.6 \%$. However, the major harmonic components are within the standard limits of IEC 6100-3-2 Class C. Fig. 9 shows the experimental results for the voltages of the devices in the proposed buck-boost type charger. As seen in Fig. 9(b), the voltage across the switched capacitor circuit is switched between the voltages of capacitors $C_{1}$ and $C_{2}$ connected in series and in parallel. When the absolute voltage of the utility voltage is smaller than half of its peak voltage, $S_{2}$ is in the on-state and the voltage across the switched capacitor circuit is equal to the capacitor voltage $\mathrm{V}_{\mathrm{C} 1}$, regardless of the 
TABLE I

MaINS PARAMETERS OF THE PROTOTYPE

\begin{tabular}{c|c|c|c}
\hline Filter & $1 \mathrm{mH}, 1 \mu \mathrm{F}$ & Inductor $\mathrm{L}_{2}$ & $2 \mathrm{mH}$ \\
\hline $\begin{array}{c}\text { Switching } \\
\text { frequency }\end{array}$ & $40 \mathrm{kHz}$ & $\begin{array}{c}\text { DC capacitors } \\
\mathrm{C}_{1}, \mathrm{C}_{2}\end{array}$ & $820 \mu \mathrm{F}$ \\
\hline Inductor $\mathrm{L}_{1}$ & $400 \mu \mathrm{H}$ & $\begin{array}{c}\text { DC capacitor } \\
\mathrm{C}_{\text {out }}\end{array}$ & $820 \mu \mathrm{F}$ \\
\hline PI controller & $\mathrm{k}_{\mathrm{p}}: 1, \mathrm{k}_{\mathrm{i}}: 100$ & & \\
\hline
\end{tabular}

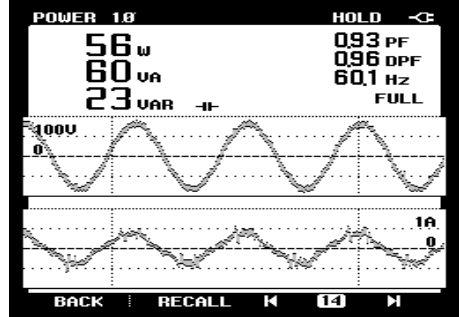

(a)

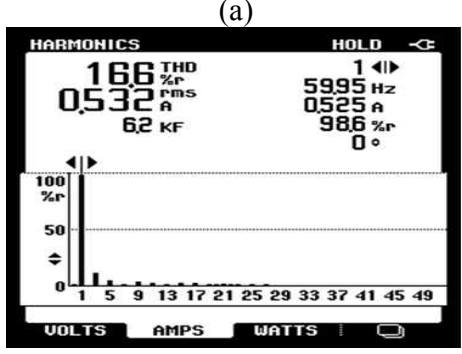

(b)

Fig. 8. Experimental result of input characteristic for the proposed buck-boost type charger. (a) Utility voltage and input current, (b) Spectrum of input current.

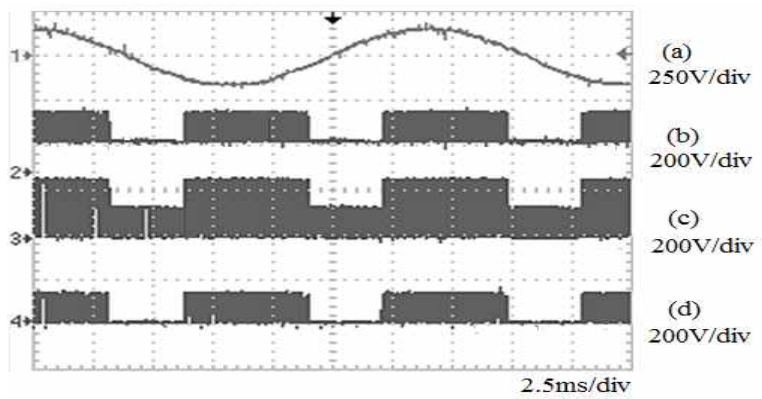

Fig. 9. Experimental result for the voltages of the devices in the proposed buck-boost type charger. (a) Utility voltage. (b) Voltage of switched capacitor circuit. (c) Voltage of $S_{1}$. (d) Voltage of $S_{2}$.

switching of $\mathrm{S}_{1}$. However, capacitors $\mathrm{C}_{1}$ and $\mathrm{C}_{2}$ are charged in series and discharged in parallel according to the switching operation of $\mathrm{S}_{1}$ while the absolute voltage of the utility voltage is higher than half of its peak voltage and $S_{2}$ is in the off-state. As seen in Fig. 8(c), the voltage of $\mathrm{S}_{1}$ is switched between the voltage of the switched capacitor circuit and zero voltage. Hence, the off-state voltage of $S_{1}$, shown in Fig.9(c), contains two $\mathrm{DC}$ voltage levels, the capacitor voltage $\mathrm{V}_{\mathrm{C} 1}$ and the summation of the capacitor voltages $V_{C 1}$ and $V_{C 2}$. Since the off-state voltage of $S_{1}$ is reduced when the absolute voltage of the utility voltage is smaller than half of its peak

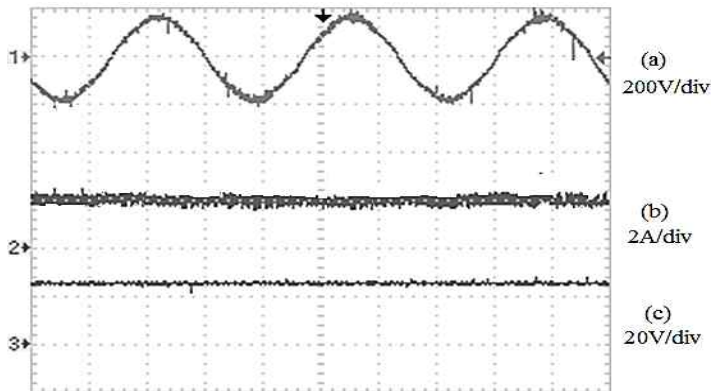

Fig. 10. Experiment result of the output characteristic for the proposed buck-boost type charger. (a) Utility voltage. (b) Charging current. (c) Battery voltage.

TABLE II

POWER EFFICIENCY

\begin{tabular}{ccc}
\hline Input power & $\begin{array}{c}\text { charger with valley- } \\
\text { fill circuit }\end{array}$ & $\begin{array}{c}\text { proposed buck-boost } \\
\text { type charger }\end{array}$ \\
\hline $36 \mathrm{~W}$ & $88.2 \%$ & $90.3 \%$ \\
$44 \mathrm{~W}$ & $90 \%$ & $90.9 \%$ \\
$56 \mathrm{~W}$ & $90.9 \%$ & $91.6 \%$ \\
$71 \mathrm{~W}$ & $91.2 \%$ & $92.6 \%$ \\
$81 \mathrm{~W}$ & $90.5 \%$ & $92 \%$ \\
\hline
\end{tabular}

voltage, the switching loss is also reduced to advance the power efficiency. Fig. 9(d) shows the voltage of $\mathrm{S}_{2}$. As seen in Fig. $9(\mathrm{~d}), \mathrm{S}_{2}$ is in the on-state and its voltage is zero when the absolute voltage of the utility voltage is smaller than half of its peak voltage. When the absolute voltage of the utility voltage is higher than half of its peak voltage, $S_{2}$ is in the off-state. Since the parallel diode of $\mathrm{S}_{2}$ is switching in complement with $\mathrm{S}_{1}$ when $\mathrm{S}_{2}$ is in the off-state, the off-state voltage of $S_{2}$ will be changed between the capacitor voltage $\mathrm{V}_{\mathrm{Cl}}$ and zero. Fig. 10 shows the charging current of the battery set. As seen in Fig. 10(b), the ripple for the charging current of the battery set is small to protect the battery set. The power efficiency of the proposed buck-boost type charger and the charger with a valley-fill circuit $\left(S_{2}\right.$ of the switched capacitor circuit is still turned off) is shown in Table II. The input power is measured by a power quality analyzer (FLUKE 43B) and the output power is measured by a digital storage oscilloscope (Tektronix TPS 2024). As seen in Table II, the power efficiency is improved by the switched capacitor circuit of the proposed buck-boost type charger.

\section{CONCLUSION}

Due to the popularization of portable electronic products and electric bikes, a low voltage charger is necessary. Therefore, a buck-boost type charger is proposed in this paper. The proposed buck-boost type charger is composed of an integrated boost/buck power converter and a switched capacitor circuit. A boost converter and a buck converter sharing a power electronic switch are integrated to be a boost/buck power converter to simplify the power circuit. The salient feature is that the switched capacitors circuit can 
control the DC link voltage with two DC voltage levels. The switched capacitor circuit can change the output voltage of the boost converter according to the utility voltage to advance the power efficiency and reduce the input voltage of the buck converter to increase the step-down voltage ratio. From the experimental results, it can be seen that the proposed buck-boost type charger can achieve a unity power factor, output a regular DC voltage, and charge the battery set.

\section{REFERENCES}

[1] D. W. Hart, Introduction to Power Electronics, Prentice Hall, 2004.

[2] V. F. Pires and J F. Silva, "Single-stage double-buck topologies with high power factor," Journal of Power Electronics, Vol. 11, No. 5, pp. 655-661, Sep. 2011.

[3] X. Xie, C. Zhao, L. Zheng, and S. Liu, "An improved buck PFC converter with high power factor," IEEE Trans. Power Electron., Vol. 28, No.5, pp. 2277-2284, May 2013.

[4] L. Huber, L. Gang, and M. M. Jovanovi'c, "Design-oriented analysis and performance evaluation of buck PFC front end," IEEE Trans. Power Electron., Vol. 25, No. 1, pp. 85-94, Jan. 2010.

[5] S. P. Yang, S. J. Chen, and J. L. Lin, "Dynamics analysis of a low-voltage stress single-stage high-power factor correction AC/DC flyback converter," IET Power Electronics, Vol. 5, No. 9, pp. 1624-1633, Sep. 2012.

[6] J. Zhang, D. D.-C. Lu, and T. Sun, "Flyback-based single-stage power-factor-correction scheme with time-multiplexing control," IEEE Trans. Ind. Electron., Vol. 57, No. 3, pp. 1041-1049, Mar. 2010.

[7] J. Chen, D. Maksimovic, and R. W. Erickson, "Analysis and design of a low-stress buck-boost converter in universal-input PFC applications," IEEE Trans. Power Electron., Vol. 21, No. 2, pp. 320-329, Feb. 2006.

[8] A. Abramovitz and K. M. Smedley, "Analysis and design of a tapped-inductor buck-boost PFC rectifier with low bus voltage," IEEE Trans. Power Electron., Vol. 26, No. 9, pp. 2637-2649, Sep. 2011.

[9] E. L. Huber, B. T. Irving, and M. M. Jovanovic, "Effect of valley switching and switching-frequency limitation on line-current distortions of DCM/CCM boundary boost PFC converters," IEEE Trans. Power Electron., Vol. 24, No. 2, pp. 3390347, Feb. 2009.

[10] Y. Fei, R. Xinbo, Y. Yang, and Y. Zhihong, "Interleaved critical current mode boost PFC converter with coupled inductor," IEEE Trans. Power Electron., Vol. 26, No. 9, pp. 2404-2413, Sep. 2011.

[11] J. W. Shin, B. C. Hyeon, and B. H. Cho "Digital control of a power factor correction boost rectifier using diode current sensing technique," Journal of Power Electronics, Vol. 9, No. 6, pp. 903-910, Nov. 2009.

[12] M. Pahlevaninezhad, P. Das, J. Drobnik, and P. K.Jain, ”A ZVS interleaved boost AC/DC converter used in plug-in electric vehicles," IEEE Trans. Power Electron., Vol. 27, No. 8, pp. 3513-3529, Aug. 2012.

[13] H. S. Athab and D. D.-C Lu, "Simple controller for single-phase power factor correction rectifier," IET Power Electron., Vol. 3, No.4, pp. 590-600, Apr. 2010.

[14] N. Genc and I. Iskender, "DSP-based current sharing of average current controlled two-cell interleaved boost power factor correction converter," IET Power Electron., Vol. 4, No .9, pp. 1015-1022, Sep. 2011.

[15] H. Ma, C. Zheng, W. Yu, B. Gu, J. S. Lai, and Q. Feng, "Bridgeless electrolytic capacitor-less valley-fill AC/DC converter for offline twin-bus light-emitting diode lighting application," IET Power Electron., Vol. 6, No. 6, pp. 1132-1141, Jun. 2013.

[16] J. H. Kim, D. Y. Cho, J. P. Hong, and G. W. Moon, "Boost integrated flyback AC-DC converter with valley fill circuit for LED light bulb," in Proc. IPEMC, Vol. 1, pp. 457-462, 2012.

[17] J. C. W. Lam and P. K. Jain, "A modified valley fill electronic ballast having a current source resonant inverter with improved line-current total harmonic distortion (THD), high power factor, and low lamp crest factor," IEEE Trans. Ind. Electron., Vol. 55, No. 3, pp. 1147-1159, Mar. 2008.

[18] I. R. Balasubramanian, S. I. Ganesan, and N. Chilakapati, "Impact of partial shading on the output power of PV systems under partial shading conditions," IET Power Electron., Vol. 7, No. 3, pp. 657-666, Mar. 2014.

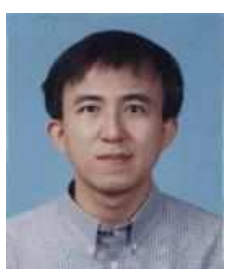

Jinn-Chang Wu was born in Tainan, Taiwan R.O.C., in 1968. He graduated from the National Kaohsiung Institute of Technology, Kaohsiung, Taiwan, in 1988, and received his M.S. and Ph.D. degrees from the National Cheng Kung University, Tainan, Taiwan, in 1992 and 2000, respectively, all in Electrical Engineering. Since 2007, he has been an Associate Professor in the Department of Microelectronic Engineering, National Kaohsiung Marine University, Kaohsiung, Taiwan. His current research interests include power electronics and their applications.

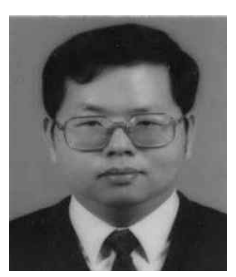

Hurng-Liahng Jou was born in Taiwan R.O.C., in 1959. He received his B.S. degree in Electrical Engineering from Chung Yuan University, Jonglih, Taiwan, in 1982, and his M.S. and Ph.D. degrees in Electrical Engineering from the National Cheng Kung University, Tainan, Taiwan, in 1984 and 1991, respectively. $\mathrm{He}$ is currently a Professor in the Department of Electrical Engineering of the National Kaohsiung University of Applied Sciences, Kaohsiung, Taiwan. His current research interests include power electronics applications and power quality improvement techniques.

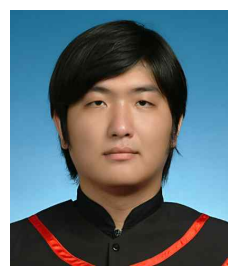

Jie-Hao Tsai was born in Kaohsiung, Taiwan R.O.C., in 1990. He received his B.S. degree in Microelectronic Engineering from the National Kaohsiung Marine University, Kaohsiung, Taiwan, in 2013. He is presently working toward his M.S. degree in Microelectronic Engineering at the National Kaohsiung Marine University. 